\title{
Impeded physical aging in PIM-1 membranes containing graphene-like fillers
}

DOI:

10.1016/j.memsci.2018.06.026

\section{Document Version}

Accepted author manuscript

Link to publication record in Manchester Research Explorer

\section{Citation for published version (APA):}

Alberto, M., Bhavsar, R., Luque-Alled, J. M., Vijayaraghavan, A., Budd, P., \& Gorgojo, P. (2018). Impeded physical aging in PIM-1 membranes containing graphene-like fillers. Journal of Membrane Science, 563, 513-520.

https://doi.org/10.1016/j.memsci.2018.06.026

\section{Published in:}

Journal of Membrane Science

\section{Citing this paper}

Please note that where the full-text provided on Manchester Research Explorer is the Author Accepted Manuscript or Proof version this may differ from the final Published version. If citing, it is advised that you check and use the publisher's definitive version.

\section{General rights}

Copyright and moral rights for the publications made accessible in the Research Explorer are retained by the authors and/or other copyright owners and it is a condition of accessing publications that users recognise and abide by the legal requirements associated with these rights.

\section{Takedown policy}

If you believe that this document breaches copyright please refer to the University of Manchester's Takedown Procedures [http://man.ac.uk/04Y6Bo] or contact uml.scholarlycommunications@manchester.ac.uk providing relevant details, so we can investigate your claim.

\section{OPEN ACCESS}




\section{Author's Accepted Manuscript}

Impeded physical aging in PIM-1 membranes containing graphene-like fillers

Monica Alberto, Rupesh Bhavsar, Jose Miguel Luque-Alled, Aravind Vijayaraghavan, Peter M. Budd, Patricia Gorgojo

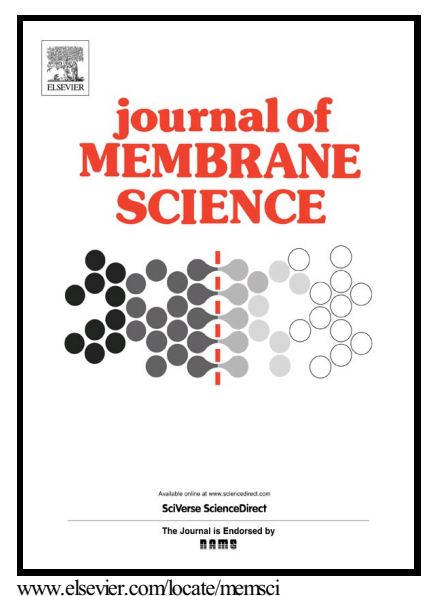

PII: $\quad$ S0376-7388(18)31057-3

DOI: $\quad$ https://doi.org/10.1016/j.memsci.2018.06.026

Reference: MEMSCI16243

To appear in: Journal of Membrane Science

Received date: 17 April 2018

Revised date: 31 May 2018

Accepted date: 16 June 2018

Cite this article as: Monica Alberto, Rupesh Bhavsar, Jose Miguel Luque-Alled, Aravind Vijayaraghavan, Peter M. Budd and Patricia Gorgojo, Impeded physical aging in PIM-1 membranes containing graphene-like fillers, Journal of Membrane Science, https://doi.org/10.1016/j.memsci.2018.06.026

This is a PDF file of an unedited manuscript that has been accepted for publication. As a service to our customers we are providing this early version of the manuscript. The manuscript will undergo copyediting, typesetting, and review of the resulting galley proof before it is published in its final citable form. Please note that during the production process errors may be discovered which could affect the content, and all legal disclaimers that apply to the journal pertain. 


\title{
ACCEPTED MANUSCRIPT
}

\section{Impeded physical aging in PIM-1 membranes containing graphene-like fillers}

Monica Alberto ${ }^{\mathrm{a}}$, Rupesh Bhavsar ${ }^{\mathrm{b}}$, Jose Miguel Luque-Alled ${ }^{\mathrm{a}}$, Aravind Vijayaraghavan ${ }^{\mathrm{c}}$, Peter M. Budd ${ }^{b}$, Patricia Gorgojo ${ }^{a}$

${ }^{a}$ School of Chemical Engineering and Analytical Science, The University of Manchester, United Kingdom

${ }^{\mathrm{b}}$ School of Chemistry, The University of Manchester, United Kingdom

${ }^{\mathrm{c}}$ School of Materials, The University of Manchester, United Kingdom

Corresponding author: p.gorgojo@manchester.ac.uk

\begin{abstract}
Physical aging of polymer of intrinsic microporosity PIM-1 is one of the major obstacles for its application as a commercial membrane material for gas separation. In this work, physical aging of PIM-1 and matrices of this same polymer containing graphene-like materials were studied. Graphene-like fillers resulted from the functionalization of graphene oxide (GO) with two alkyl chains of different lengths, using octylamine (OA) and octadecylamine (ODA), and further chemical reduction. Extents of membrane aging were evaluated through changes in gas permeability over time; the separation of gas mixtures comprising carbon dioxide and methane, which are of great interest for industrial applications such as the production of biogas or the purification of natural gas, was carried out. 50:50 vol. \% $\mathrm{CO}_{2} / \mathrm{CH}_{4}$ mixtures were used as feed and separation performance analysed for fresh membranes and at intervals of approximately a month up to 155 days. At the end of this testing period, aged PIM-1 membranes showed a $\mathrm{CO}_{2}$ permeability of $(2.0 \pm 0.7) \times 10^{3}$ Barrer, which corresponds to $\mathrm{a} \mathrm{CO}_{2}$ permeability reduction of $68 \%$ from the value obtained right after their fabrication. The addition of alkyl-functionalized GO is shown to be an efficient strategy to retard the physical aging of PIM-1 membranes; filler loadings as low as $0.05 \mathrm{wt} \%$ of reduced octylfunctionalized GO showed a $\mathrm{CO}_{2}$ permeability of $(3.5 \pm 0.6) \times 10^{3}$ Barrer after 5 months, which is almost three quarters higher than that of pure PIM-1 membrane aged for the same time period and represents a reduction of just $39 \%$ from its initial value. Moreover, the addition of graphene-like materials to PIM-1 does not affect its mechanical properties.
\end{abstract}




\section{ACCEPTED MANUSCRIPT}

\section{Graphical abstract}

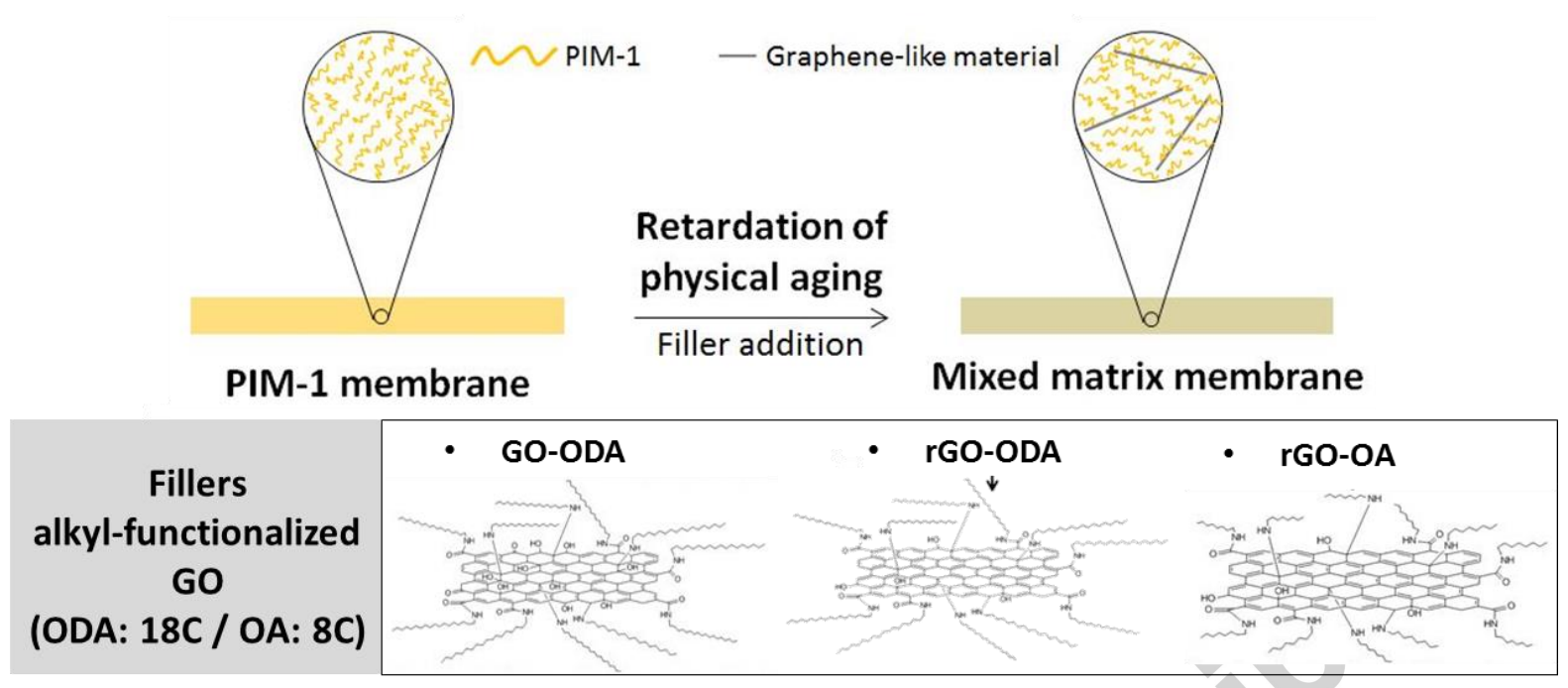

\section{Highlights}

- Physical aging of mixed matrix membranes (MMMs) composed of PIM-1 and graphene-like materials was investigated.

- A binary $\mathrm{CO}_{2} / \mathrm{CH}_{4}(50: 50$ vol.\%) gas mixtures was used.

- Physical aging was reduced by the incorporation of reduced alkyl- functionalized graphene oxide nanosheets into PIM-1 matrices.

- Low filler loadings led to higher reduction in physical aging.

\section{Keywords}

$\mathrm{CO}_{2}$ separation; Gas separation; Graphene; mixed matrix membranes; physical aging; PIM-1; polymer of intrinsic microporosity. 


\section{ACCEPTED MANUSCRIPT}

\section{Introduction}

In recent years capture of carbon dioxide $\left(\mathrm{CO}_{2}\right)$ has been a subject of intense research due to its potential contribution in the prevention of global climate change. $\mathrm{CO}_{2}$ is inevitably emitted into the atmosphere from naturally-occurring processes such as decomposition, ocean release, respiration or the degassing of magma in volcanic areas. However, human activities, including the burning of fossil fuels, deforestation and the livestock sector, are responsible for almost all the increase in $\mathrm{CO}_{2}$ emissions over the past few decades. A recent report released by the World Meteorological Organization identified the atmospheric $\mathrm{CO}_{2}$ concentration as the highest in 800,000 years and it is expected to rise in the coming decades [1].

In the light of these discouraging predictions and the fact that fossil fuels are finite energy sources, an increase in the use of renewable energy resources must be a global priority. Biogas is an alternative to fossil fuels. It is produced from anaerobic digestion of organic wastes and agricultural by-products and reduces $\mathrm{CO}_{2}$ emissions by completing the carbon cycle. It is mainly composed of $\mathrm{CH}_{4}$ and $\mathrm{CO}_{2}$ with small amounts of hydrogen sulphide, and as in natural gas the presence of $\mathrm{CO}_{2}$ and other acid gases reduces its calorific value and causes pipeline corrosion, which makes its handling, transport and storage difficult and expensive $[2,3]$.

The development of economic and effective techniques to separate $\mathrm{CO}_{2}$ from other gases such as $\mathrm{CH}_{4}$ has attracted great interest over the past few years. Cryogenic separation and amine scrubbing technologies are conventional operations for such purpose. However, these methods are characterized by their high energy requirements, complex equipment and operation and high capital investment $[2$, 4]. Other techniques, including membrane-based separations, are seen as potential alternatives which feature low energy demand, little maintenance cost, and ease of operation and scale-up [2].

Among all materials currently available for the fabrication of $\mathrm{CO}_{2}$-selective membranes, polymers of intrinsic microporosity (PIMs) have received great attention since the publication of the first PIMbased membrane [5]. PIM-1 is by far the most investigated PIM since it is soluble in certain common organic solvents such as chloroform and tetrahydrofuran, which allows the fabrication of membranes 


\section{ACCEPTED MANUSCRIPT}

through conventional solution-processing techniques [6-8]. In addition, it features high free volume as a result of frustrated packing of polymer chains due to spiro-sites of contortion in the rigid ladder polymer chain that give rise to a randomly contorted structure [9-11]. Due to its high free volume PIM-1 is highly $\mathrm{CO}_{2}$ permeable, and it is $\mathrm{CO}_{2}$-selective and shows good chemical, mechanical and thermal stability [10].

Despite being a promising polymer for gas separation applications, PIM-1 presents pronounced physical aging in addition to the well-known trade-off between membrane permeability and selectivity common to all polymeric membranes, therefore hindering its commercialization [12]. Physical aging occurs in non-equilibrium glassy polymers and leads to the loss of free volume and consequent decline in permeability with time due to the segmental rearrangements approaching an equilibrium state $[13,14]$. This phenomenon is less pronounced over time as the excess free volume within the membranes, which is the driving force for physical aging, gradually decreases [13]. Because of the intense loss in membrane performance over time, long-term stability represents a major challenge in the application of glassy polymer membranes in successful commercial gas separation technologies [15].

Studies have shown that physical aging is dependent on the film thickness, [15-18], temperature [19], storage conditions (e.g. temperature, atmosphere and pressure) [16] and membrane treatment $[10,20$ 23]. In addition, the experimental testing methodology (i.e. continuous or momentary) can also lead to different results [24]. Several strategies have been developed, aiming at the retardation of the physical aging of polymeric membranes including UV-treatment [25] UV photo-oxidation [26], surface modification [27], cross-linking [26, 28] and the addition of fillers to obtain a hybrid membranes, typically referred to as mixed matrix membranes (MMMs) $[12,21,29,30]$.

Graphene has been applied with great success in numerous fields, including membrane-based separation processes [31]. $\mathrm{CO}_{2}$ sorption of PIM-1/graphene membranes was studied previously by Gonciaruk et. al. [32]; no significant change in $\mathrm{CO}_{2}$ sorption was found in this work, however it has been previously reported that graphene can disrupt the polymer chains and, therefore, enhance the membrane permeability without affecting its selectivity [33]. In addition, it is suggested there is an 


\section{ACCEPTED MANUSCRIPT}

alignment between the PIM-1 polymer segments and graphene flakes, which may also prevent the mobility of the polymer chains and therefore the physical aging of the membrane.

Driven by this hypothesis, in this paper the physical aging of PIM-1/graphene MMMs was investigated. Pure PIM-1 membranes and MMMs containing graphene-like materials were prepared and their gas separation performance for $\mathrm{CO}_{2} / \mathrm{CH}_{4}$ mixtures monitored over 155 days. Fillers included graphene oxide (GO) functionalized with two types of alkyl chains of different lengths, using octylamine (OA) and octadecylamine (ODA), and further chemical reduction. These graphene-based fillers were used due to their good dispersion and stability in chloroform as shown in our previous study [31]. The mechanical stability of the hybrid membranes was also investigated.

\section{Experimental}

\subsection{Materials}

Tetrafluoroterephthalonitrile (TFTPN, Sigma Aldrich, UK) was purified through sublimation at 150 ${ }^{\circ} \mathrm{C}$ and then collected without vacuum. 5,5',6,6'-Tetrahydroxy-3,3,3',3'-tetramethyl-1,1'spirobisindane (TTSBI, Aesar, UK) was dissolved in methanol and precipitated in dichloromethane (DCM, Sigma Aldrich, UK) before use. Chloroform, methanol, octadecylamine (ODA), octylamine $(\mathrm{OA})$, potassium carbonate $\left(\mathrm{K}_{2} \mathrm{CO}_{3}\right)$, dimethylacetamide (DMAc), toluene and hydrazine monohydrate ( $\sim 0$ vol.\% in $\mathrm{H}_{2} \mathrm{O}$ ) were purchased from Sigma Aldrich. Graphite was purchased from NGS Naturegraphit GmbH (Germany). Potassium permanganate was purchased from Aesar (UK). Ammonia was procured from Acros Organics (United Kingdom). Apart from TFTPN and TTSBI, all the other chemicals were used as received.

\subsection{Synthesis of PIM-1}

PIM-1 was synthetized by following the procedure reported in the literature by Du et. al. [34]. TFTPN (0.05 mol, $10.00 \mathrm{~g})$, TTSBI (0.05 mol, $17.29 \mathrm{~g})$ and $\mathrm{K}_{2} \mathrm{CO}_{3}(0.15 \mathrm{~mol}, 20.73 \mathrm{~g})$, DMAc (100 mL) and toluene $(50 \mathrm{~mL})$ were reacted under nitrogen at $160{ }^{\circ} \mathrm{C}$ and reflux and constant mechanical stirring for $40 \mathrm{~min}$. A highly viscous solution was obtained at the end of the reaction, which was then poured into methanol and the crude product collected through vacuum filtration. After that, the yellow crude 


\section{ACCEPTED MANUSCRIPT}

product obtained was dissolved in chloroform and re-precipitated in methanol. The recovered precipitated product was refluxed overnight in water at $100{ }^{\circ} \mathrm{C}$ and then dried at $110{ }^{\circ} \mathrm{C}$ overnight.

\subsection{Synthesis of alkyl-functionalized graphene oxide materials}

Graphene oxide (GO) was synthetized through a modified Hummers' method as described previously by Rourke et al. [35]. The $\mathrm{pH}$ of a GO aqueous solution $\left(120 \mathrm{mg}, 1 \mathrm{mg} \mathrm{mL}^{-1}\right)$ was adjusted to 10 with ammonia. Following this, either ODA or OA $(1.2 \mathrm{~mol})$ were dissolved in ethanol, added gradually to the GO aqueous solution under stirring and left for $24 \mathrm{~h}$ at $60{ }^{\circ} \mathrm{C}$. The final products were washed with ethanol in order to remove the unreacted alkylamine and chloroform. The obtained product from the functionalization of GO using $\mathrm{OA}$, named GO-OA, could not be dispersed in chloroform, and therefore had to be chemically reduced in order to be used as a filler for the preparation of membranes. In contrast, the alkyl-functionalized GO using ODA (GO-ODA), was successfully dispersed in chloroform and therefore also used in this study as filler before and after its chemical reduction.

The reduction of alkyl-functionalized GO was done by adding hydrazine monohydrate $(0.12 \mathrm{~mL}, 80$ $\%$ vol) to GO-OA or GO-ODA aqueous solutions and stirring for $2 \mathrm{~h}$ at $90{ }^{\circ} \mathrm{C}$. Reduced samples were named rGO-OA and rGO-ODA, and both dispersed well in chloroform.

\subsection{Membrane preparation}

The alkyl-functionalized GO materials were dispersed in chloroform by means of a probe sonicator (Cole-Parmer, $750 \mathrm{~W}, 20 \mathrm{kHz}$, amplitude 22\% - Cole-Parmer Instrument, USA) for $10 \mathrm{~min}$ in discontinuous mode (pulse on for $9 \mathrm{~s}$ and pulse off for $9 \mathrm{~s}$ ). These dispersions were then added to a PIM-1 solution (4 wt.\% of polymer) in chloroform and were magnetically stirred for $1 \mathrm{~h}$ before casting. Different loadings of rGO-OA, rGO-ODA and GO-ODA (0.01 wt.\%, 0.05 wt. $\%, 0.1$ wt. $\%$ and 0.25 wt.\% with regards to the mass of the polymer) were used in the membrane preparation as indicated in Table 1. 


\section{ACCEPTED MANUSCRIPT}

Casting solutions were poured into glass petri dishes, covered with their lids and were left in an inhouse made cabinet under continuous flow of nitrogen for 3 days. After that, membranes were soaked in methanol for 1day and then put in the oven overnight at $80{ }^{\circ} \mathrm{C}$ in order to remove any trapped residual solvents.

Table 1. Fabricated membranes with theoretical and experimental (obtained through UV analysis of redissolved membranes) filler loadings, and thickness after methanol treatment and vacuum.

\begin{tabular}{ccccc}
\hline Membrane code & Filler & $\begin{array}{c}\text { wt.\% of filler } \\
\text { Theoretical values }\end{array}$ & $\begin{array}{c}\text { wt.\% of filler } \\
\text { Experimental } \\
\text { values }\end{array}$ & $\begin{array}{c}\text { Membrane } \\
\text { thickness }(\boldsymbol{\mu m})\end{array}$ \\
\hline PIM-1 & - & - & - & $40 \pm 10$ \\
\hline 0.01 GO-ODA & & 0.01 & $0.030 \pm 0.015$ & $52 \pm 3$ \\
0.05GO-ODA & GO-ODA & 0.05 & $0.067 \pm 0.004$ & $45 \pm 9$ \\
0.1GO-ODA & & 0.1 & $0.140 \pm 0.050$ & $52 \pm 2$ \\
0.25GO-ODA & & 0.25 & $0.220 \pm 0.080$ & $51 \pm 7$ \\
\hline 0.01rGO-ODA & & 0.01 & $0.009 \pm 0.001$ & $41 \pm 4$ \\
0.05rGO-ODA & rGO-ODA & 0.05 & $0.052 \pm 0.004$ & $43 \pm 9$ \\
0.1rGO-ODA & & 0.1 & $0.110 \pm 0.0075$ & $36 \pm 6$ \\
0.25rGO-ODA & & 0.25 & $0.366 \pm 0.086$ & $42 \pm 11$ \\
\hline 0.01rGO-OA & & 0.01 & $0.034 \pm 0.002$ & $46 \pm 2$ \\
0.05rGO-OA & rGO-OA & 0.05 & $0.126 \pm 0.027$ & $53 \pm 4$ \\
0.1rGO-OA & & 0.1 & $0.184 \pm 0.010$ & $48 \pm 10$ \\
0.25rGO-OA & & 0.25 & $0.408 \pm 0.023$ & $62 \pm 5$ \\
\hline
\end{tabular}

\subsection{Characterization of fillers and membranes}

The weight-average molar mass of PIM-1 synthesized for this study was analysed through gel permeation chromatography (GPC). This analysis was performed using a multi-detector Viscotek GCPmax VE 2001 chromatograph (Malvern, UK) equipped with two PLgel mixed-B columns and Viscotek TDA302 tripe detector array. The analysis was performed in chloroform at a flow rate of 1 $\mathrm{mL} \mathrm{min}^{-1}$. OmniSEC software (Malvern, UK) was used to analyze the data. The polymer was dissolved in chloroform at a concentration of $1 \mathrm{mg} \mathrm{mL}^{-1}$.

The loadings of graphene-based materials into the polymer matrices were examined through UV-Vis spectroscopy (Genesys $10 \mathrm{~S}$ UV-Vis spectrophotometer, Thermo Scientific, United Kingdom). Membranes were cut into small pieces and re-dissolved in chloroform and the absorbance of such solutions was registered at a wavelength of $660 \mathrm{~nm}$. The concentration was determined using the 


\section{ACCEPTED MANUSCRIPT}

Beer-Lambert law; the extinction coefficients used for GO-ODA, rGO-ODA, and rGO-OA were 4.939, 15.256, and $7.556 \mathrm{~mL} \mathrm{mg}^{-1} \mathrm{~cm}^{-1}$, respectively [31].

Membrane morphology was studied by scanning electron microscopy (SEM) with a FEI Quanta 250 FEG instrument (FEI, USA) at $15 \mathrm{kV}$. All samples were prepared by immersing them firstly in ethanol for $30 \mathrm{~s}$ and then transferring them into liquid nitrogen for another $30 \mathrm{~s}$, before being snapped. Platinum (Pt) sputter coating (MTM 10 Thickness Monitor (Cressington, USA)) was applied onto all samples before imaging. The thickness of the membranes was measured using a digital micrometer screw gauge (Mitutoyo IP65 Coolant Proof, UK) with an accuracy of $\pm 0.5 \mu \mathrm{m}$ and verified under SEM. The membrane thickness resulted from the average of at least 5 points on each membrane.

Mechanical properties of membranes were determined by performing uniaxial tensile tests utilizing an Instron 5542 tensiometer (Instron, USA), equipped with Bluehill 3 software and a $10 \mathrm{~N}$ loading cell. The initial gauge length and width were $15 \mathrm{~mm}$ and $3 \mathrm{~mm}$, respectively. A contact elongation rate of 1 $\mathrm{mm} \min ^{-1}$ was set. Tensile tests were performed at ambient temperature. Samples were cut with scissors, and five different samples for each type of membrane were tested under the same conditions in order to ensure reproducibility. Membranes were approximately 2 months old when tested. Elongation at break, ultimate tensile strength (UTS) and young's modulus were calculated from the stress-strain curve obtained. Elongation at break, $\varepsilon_{\text {breakage}}$, refers to the ratio between the change in length and the initial length of the specimen at breakage and is calculated with equation (3) as follows:

$$
\varepsilon_{\text {breakage }}=\frac{l_{\varepsilon_{\text {breakage }},}-l_{0}}{l_{0}} \times 100 \%
$$

Where $l_{0}$ and $l_{\varepsilon_{\text {breakage }}}$, are the initial and length and breakage lengths, respectively. UTS is defined as the maximum stress withstood by the material. Finally, the Young's modulus measures the stiffness of the material and is defined as the gradient between the stress applied to the strain in the elastic region of the deformation. 


\section{ACCEPTED MANUSCRIPT}

Gas permeation measurements were done at $25{ }^{\circ} \mathrm{C}$ using a $\mathrm{CO}_{2} / \mathrm{CH}_{4}$ binary gas mixture in a volume ratio of 50:50 vol.\% as feed (flowrate of $25 \mathrm{~mL} \mathrm{~min}^{-1}$ for each gas). A schematic diagram of the apparatus used for the gas permeation measurements is shown in Fig. 1; a pressurized binary mixture (at approximately 3 bar) was applied to the upstream side of the membrane cell, and sweep gas He at a flowrate of $25 \mathrm{~mL} \mathrm{~min}{ }^{-1}$ was passed on the downstream side of the membrane at atmospheric pressure. The composition of permeate was analysed using a 490 micro gas chromatography system (Agilent, USA). Gas permeability was recorded once steady-state was reached. Membranes were tested fresh right after their preparation and methanol treatment (day 0) and at days 35, 63, 92, 128 and 155 using the same gas composition, temperature and transmembrane pressures.

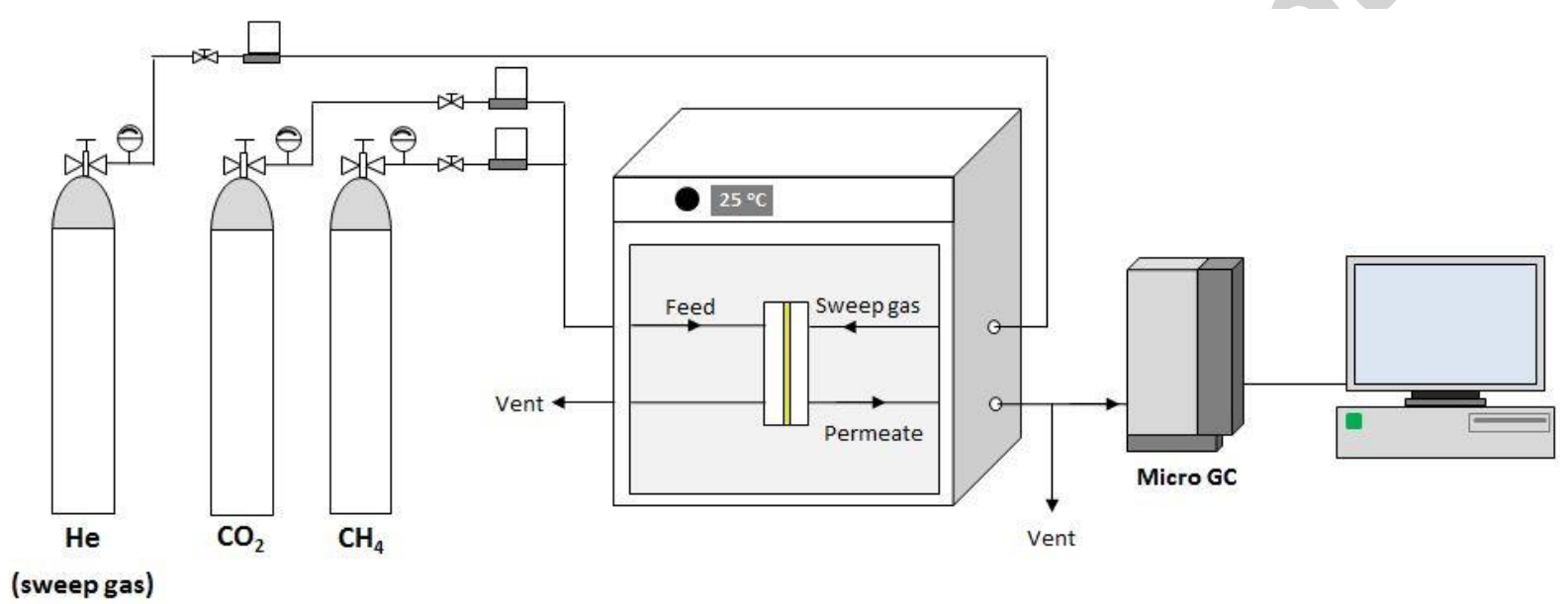

Fig. 1. Schematic diagram of the setup used for gas permeation measurements.

Due to the nature of the experimental work, where the same membrane had to be tested several times and stored in between gas separation experiments, fabricated MMMs were mounted on aluminium discs using epoxy resin to seal. The effective areas of the membranes were in the range $0.09-0.56$ $\mathrm{cm}^{2}$.

The gas permeability was calculated using equation (1):

$$
P=\frac{Q l}{A \Delta p}
$$




\section{ACCEPTED MANUSCRIPT}

Where $P$ is the permeability in Barrer $\left(1\right.$ Barrer $\left.=10^{-10} \mathrm{~cm}^{3}[\mathrm{STP}] \mathrm{cm} \mathrm{cm}^{-2} \mathrm{~s}^{-1} \mathrm{cmHg}^{-1}\right), Q$ is the permeate gas flow rate $\left(\mathrm{cm}^{3}(\mathrm{STP}) \mathrm{s}^{-1}\right), l$ is the membrane thickness $(\mathrm{cm}), A$ is the effective membrane area $\left(\mathrm{cm}^{2}\right)$ and $\Delta p$ is the pressure difference across the membrane $(\mathrm{cmHg})$. In SI units 1 Barrer is equal to $3.34 \times 10^{-16} \mathrm{~mol} \mathrm{~m} \mathrm{~m}^{-2} \mathrm{~s}^{-1} \mathrm{~Pa}^{-1}$. The selectivity for the gas pair $\mathrm{A}$ and $\mathrm{B}\left(\alpha_{\mathrm{A} / \mathrm{B}}\right)$ is given by the equation (2):

$$
\alpha_{A / B}=\frac{P_{A}}{P_{B}}
$$

where $P_{\mathrm{A}}$ and $P_{\mathrm{B}}$ are the permeability coefficients for gases A and $\mathrm{B}$, respectively.

\section{Results and discussion}

The weight-average molar mass of synthesized PIM-1used for the preparation of membranes was $123,410 \mathrm{~g} \mathrm{~mol}^{-1}$ with a polydispersity value of 3.1 as obtained via GPC. The filler loading for each cast membrane was analysed through UV-Vis, as shown in Table 1. The experimental filler loadings (i.e. real concentrations in the dried membranes) were within the same order of magnitude of those calculated for the preparation of casting solutions, with 2-3 fold differences in some cases possibly due to solvent evaporation during UV sample preparation and analysis.

SEM images of cross sections and surfaces of the membranes are shown in Fig. 2 and Fig. S1. The cross section of a pure PIM-1 membrane (Fig. 2a) shows a continuous and defect-free polymer layer. Cross-sections of the MMMs (Fig. 2b and Fig. S1a-f) also reveal continuous films in which big agglomerates are not observed. The incorporation of fillers might affect the morphology of polymeric membranes; however MMMs in this work preserve the typical dense structure of pure PIM-1, possibly as a result of the very low concentrations, with filler loadings not exceeding $0.25 \mathrm{wt} . \%$ [31]. Similarly to pure PIM-1 membranes, MMMs show a smooth surface; however, some nanoholes with an average diameter of $0.37 \mu \mathrm{m}$ are observed and are indicated with arrows on the micrographs in Fig. 2 and Fig. S1. These nanoholes are likely formed due to the evaporation of chloroform during membrane formation and are only observed on the very surface; it is evident from the cross-section SEM images that the holes do not span the entire thickness, hence membrane performance should not be undermined. However, their presence should be evaluated more extensively in thin film composite 


\section{ACCEPTED MANUSCRIPT}

membranes where selective PIM-1 layers are reduced to a few micrometers or even few tens or hundreds of nanometres.

(a)

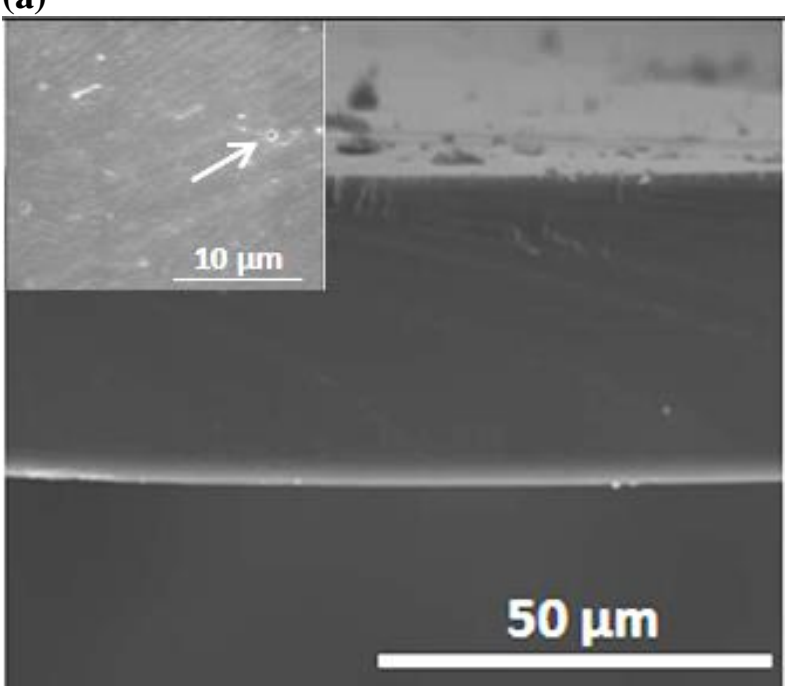

(b)

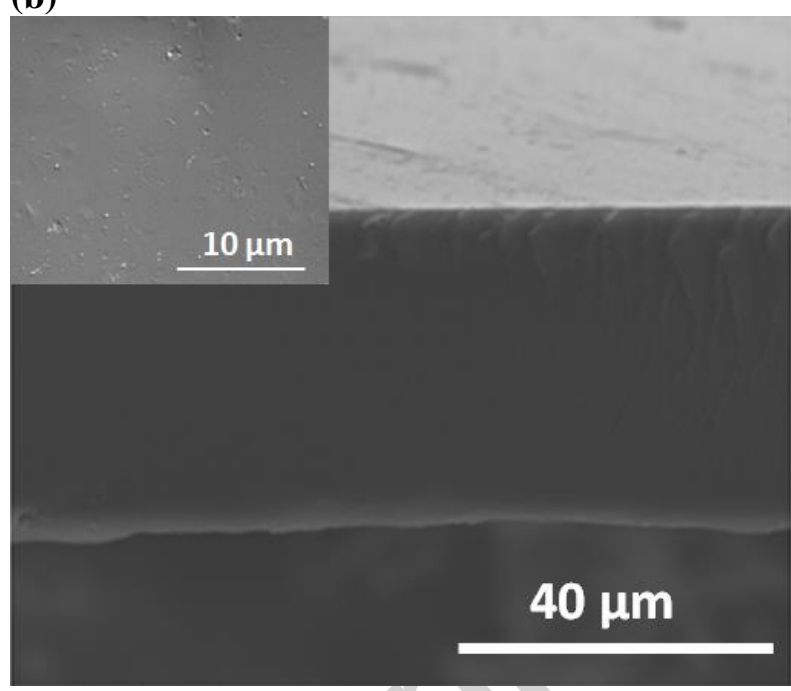

Fig. 2. Cross section and surface (insets) SEM images of (a) PIM-1 and (b) 0.1GO-ODA membranes. Arrows indicates superficial holes on the membranes.

Uniaxial tensile tests were performed on all the membranes in order to investigate their mechanical properties by assessing the Young's modulus (MPa), UTS (MPa) and elongation at break (\%). Obtained values for pristine PIM-1 and MMMs are shown in Table 2. Pure PIM-1 membranes have a Young's modulus of $1.00 \pm 0.21 \mathrm{GPa}$, a UTS of $41.7 \pm 7.1 \mathrm{MPa}$ and an elongation at break of $7.0 \pm$ $1.7 \%$, which are in good agreement with values for pure PIM-1 freestanding membranes found in the literature [36-38].

Furthermore, MMMs prepared in this work present similar mechanical properties than bare PIM-1 membranes, as seen in Table 2. Some improvements can be inferred from the obtained data, but caution has to be taken given the spread in the values. This might be due to the variability in the materials properties such as the random orientation flakes within the polymer matrix. Fig. S2 in the supporting information contains stress-strain curves obtained for PIM-1, 0.05GO-ODA, 0.05rGOODA and 0.05 rGO-OA. The maximum increase in Young's modulus of $35 \%$ was achieved by a membrane containing $0.1 \mathrm{wt} . \%$ rGO-ODA. As an example, the membrane with code $0.1 \mathrm{GO}-\mathrm{ODA}$ (0.1 wt.\% octadecyl-functioinalized GO) presented an average UTS of $46.2 \pm 3.3 \mathrm{MPa}$, which represents an increase of approximately 7\% over pristine PIM-1 membranes. The enhancement in the 


\section{ACCEPTED MANUSCRIPT}

mechanical properties observed for some of the MMMs can be attributed to the good dispersion and compatibility between the fillers and the PIM-1 polymer matrix. This consequently leads to a successful load-transfer between the continuous and the dispersed phases of the membranes [3941]. In addition, the increase in elongation at break at lower alkyl-functionalized GO loading might be due to the intrinsic mechanical properties of graphene [42]. Further increase of concentrations in the PIM-1 polymer matrix (0.25 wt.\%) suggests a decline of the mechanical properties of the membranes. As seen in previous studies, this phenomenon can be attributed to filler agglomeration, and consequent reduction of effective interaction between the filler and the polymer matrix, leading to an inefficient stress transfer from matrix to filler [41, 43, 44].

Table 2. Summary of the mechanical properties of pristine PIM-1 and MMMs.

\begin{tabular}{cccc}
\hline \multirow{2}{*}{ Membrane } & $\begin{array}{c}\text { Young's Modulus } \\
(\mathbf{G P a})\end{array}$ & $\begin{array}{c}\text { Ultimate tensile strength } \\
(\mathbf{M P a})\end{array}$ & $\begin{array}{c}\text { Elongation at break } \\
(\boldsymbol{\%})\end{array}$ \\
\hline PIM-1 & $1.01 \pm 0.21$ & $41.7 \pm 7.1$ & $7.0 \pm 1.7$ \\
0.01GO-ODA & $1.02 \pm 0.13$ & $40.7 \pm 6.2$ & $10.8 \pm 6.5$ \\
0.05GO-ODA & $1.09 \pm 0.10$ & $44.2 \pm 4.6$ & $10.1 \pm 4.1$ \\
0.1GO-ODA & $1.20 \pm 0.28$ & $46.2 \pm 3.3$ & $7.4 \pm 2.9$ \\
0.25GO-ODA & $0.93 \pm 0.30$ & $40.2 \pm 8.3$ & $6.6 \pm 1.5$ \\
0.01rGO-ODA & $1.14 \pm 0.08$ & $40.2 \pm 2.6$ & $6.9 \pm 1.9$ \\
0.05rGO-ODA & $1.01 \pm 0.13$ & $43.5 \pm 3.2$ & $10.1 \pm 2.8$ \\
0.1rGO-ODA & $1.36 \pm 0.46$ & $38.4 \pm 6.6$ & $6.7 \pm 3.1$ \\
0.25rGO-ODA & $1.19 \pm 0.28$ & $44.4 \pm 4.6$ & $7.7 \pm 1.7$ \\
0.01rGO-OA & $1.08 \pm 0.01$ & $44.0 \pm 7.1$ & $7.8 \pm 3.9$ \\
0.05rGO-OA & $0.96 \pm 0.03$ & $45.2 \pm 2.0$ & $7.3 \pm 1.3$ \\
0.1rGO-OA & $1.05 \pm 0.12$ & $44.4 \pm 5.1$ & $9.5 \pm 2.2$ \\
0.25rGO-OA & $1.05 \pm 0.17$ & $39.6 \pm 6.7$ & $6.4 \pm 2.6$ \\
\hline
\end{tabular}

Gas permeation measurements were carried out to evaluate the physical aging in pristine PIM-1 membranes and MMMs up to 155 days, with permeability data for days 0 (fresh membranes right after preparation and methanol treatment), 35, 63, 92, 128 and 155. Binary $\mathrm{CO}_{2} / \mathrm{CH}_{4}$ gas mixtures at $25{ }^{\circ} \mathrm{C}$ with a transmembrane pressure of 2 bar were used. Fig. 3 shows the $\mathrm{CO}_{2}$ and $\mathrm{CH}_{4}$ permeabilities for membranes containing different fillers in the polymer matrix. Tables S3, S4 and S5 show $\mathrm{CO}_{2}$ and $\mathrm{CH}_{4}$ permeability values and $\mathrm{CO}_{2} / \mathrm{CH}_{4}$ selectivities for all the membranes represented in Fig. 3.

Prepared freestanding pure PIM-1 membranes showed initial (day 0) $\mathrm{CO}_{2}$ and $\mathrm{CH}_{4}$ permeabilities and selectivity of $(6.4 \pm 1.3) \times 10^{3}$ and $(3.3 \pm 1.3) \times 10^{2}$ Barrer and $20.3 \pm 3.5$, respectively. These values 
are in good agreement with others found in the literature for PIM-1 [10, 21, 29]. Compared with values for MMMs also at day 0 , it is observed that the addition of graphene-like nanosheets into the PIM-1 polymer matrix leads to a decrease in permeability which, in general, is more evident as the filler concentration increases; the presence of such non-porous fillers increases the tortuosity so that gas molecules have to diffuse across longer distances in the membrane. This behaviour does not support the results previously reported on PIM-1 MMMs containing few-layer graphene [33], where more than a two-fold increase in $\mathrm{CO}_{2}$ permeability was achieved with a graphene loading of $\sim 0.001$ wt.\% (0.05 vol.\%) as a consequence of the disruption of polymer chains. This discrepancy can be due to differences in the nature of the fillers as well as in membrane preparation and testing.

As expected, $\mathrm{CO}_{2}$ and $\mathrm{CH}_{4}$ permeabilities of freestanding pure PIM-1 and MMMs decreased progressively over the period tested. The $\mathrm{CO}_{2}$ permeability of pristine polymeric membranes dropped approximately by half after a 2 -month period (from $(6.4 \pm 1.3) \times 10^{3}$ down to $(3.5 \pm 1.1) \times 10^{3}$ Barrer), and gradually decreased after that down to $(2.0 \pm 0.7) \times 10^{3}$ Barrer (value obtained at day 155). Similar behaviour of PIM-1 membranes is reported in the literature [10, 21]. MMMs also aged with time and gas permeabilities decreased for such membranes; however, the reduction after 155 days was in all cases lower than that of PIM-1 without fillers (i.e. lower than $68 \%$ ), which suggests retardation of the physical aging due to the incorporation of alkyl-functionalized GO nanosheets into the polymer matrices. After 155 days, $\mathrm{CO}_{2}$ permeability values for $0.05 \mathrm{GO}-\mathrm{ODA}, 0.05 \mathrm{rGO}-\mathrm{ODA}$ and 0.05 rGO-OA were $(3.0 \pm 0.2) \times 10^{3},(2.4 \pm 0.6) \times 10^{3}$ and $(3.5 \pm 0.6) \times 10^{3}$ Barrer, respectively, which correspond to a lower reduction of 46,49 and $39 \%$. That is, the $\mathrm{CO}_{2}$ permeability of the aged 0.05 rGO-OA was approximately $73 \%$ higher than that of pure PIM-1 membrane aged for 155 days.

This behaviour confirms the results presented by Gonciaruk et al. [32], in which the potential reduction of physical aging was attributed to the constriction of polymer chain motion due to alignment of graphene sheets and polymer segments [32]. According to our results, all MMMs still suffer from aging to some extent; however, their $\mathrm{CO}_{2}$ permeability reduction is always lower than that of pristine PIM-1 membranes. Plots with the fraction of initial permeability as a function of time for PIM-1 and MMMs containing GO-ODA, rGO-ODA and rGO-OA are shown in Figures S3, S4 and 


\section{ACCEPTED MANUSCRIPT}

S5, respectively. Exceptionally, membranes 0.25 GO-ODA and 0.25 GO-ODA, both presented a reduction in $\mathrm{CO}_{2}$ permeability of $62 \%$, which is very close to that of PIM-1 without fillers after the same period of 155 days. As anticipated, the initial $\mathrm{CO}_{2}$ permeabilities for these membrane $(4.5 \pm 1.0$ $\mathrm{x} 10^{3}$ and $5.5 \pm 1.1 \times 10^{3}$ Barrer) was lower than the permeability of a pure PIM-1 membrane, (6.4 \pm 1.3) $\mathrm{x} 10^{3}$ Barrer, due to the increased tortuosity of the hybrid material. However, the drop in permeability after 92 days of aging is as pronounced as that of pure PIM-1 for the MMM containing 0.25 wt.\% of filler GO-ODA (Fig. S3), or even more pronounced for the MMM containing 0.25 wt.\% of rGO-ODA (Fig. S4). The latter presents a fraction of initial $\mathrm{CO}_{2}$ permeability below that for pure PIM-1 even after 35 days of aging. This behaviour at higher loadings of functionalised GO fillers suggests higher disruption of the polymer chains at the polymer-graphene interface, which can lead to the formation of voids or higher free volume surrounding the nanosheets. This is thus more noticeable as the concentration of filler in the polymer matrix increases, adding extra volume that can be lost over time.

The permeability of $\mathrm{CH}_{4}$ also decreased over time following a similar trend to $\mathrm{CO}_{2}$. After 155 days, the permeability of $\mathrm{CH}_{4}$ decreased by $79 \%, 61 \%, 65 \%$ and $60 \%$ in PIM-1, 0.05GO-ODA, 0.05rGOODA and $0.05 \mathrm{rGO}-\mathrm{OA}$ membranes, respectively. The higher reduction in permeability of $\mathrm{CH}_{4}$ for PIM-1 membranes and MMMs was anticipated as diffusion of bigger gas molecules are affected to a greater extent by the reduction of free volume.

Regarding the $\mathrm{CO}_{2} / \mathrm{CH}_{4}$ selectivity for all the tested membranes, values increased as membranes aged with time. Fig. 4 shows the changes in $\mathrm{CO}_{2} / \mathrm{CH}_{4}$ selectivity up to 155 days. Pristine PIM-1 membranes initially showed the highest $\mathrm{CO}_{2} / \mathrm{CH}_{4}$ selectivity when compared to MMMs, possibly due to non-selective voids at the polymer-graphene interface that might be created during membrane formation. After 5 months of aging, pristine PIM-1 membranes presented a $\mathrm{CO}_{2} / \mathrm{CH}_{4}$ selectivity of 30 \pm 4.7, and 0.05GO-ODA, 0.05rGO-ODA and 0.05rGO-OA membranes had a $\mathrm{CO}_{2} / \mathrm{CH}_{4}$ selectivity of, $23.7 \pm 1.6,29.1 \pm 3.2$ and $22.9 \pm 1.1$, respectively. After the same test period of 155 days, MMMs presented higher $\mathrm{CO}_{2}$ permeabilities $\left((2.0 \pm 0.7) \times 10^{3}\right.$ Barrer for pure PIM-1 vs $(3.0 \pm 0.2) \times 10^{3},(2.4$ $\pm 0.6) \times 10^{3}$ and $(3.5 \pm 0.6) \times 10^{3}$ Barrer for 0.05GO-ODA, 0.05rGO-ODA and 0.05rGO-OA membranes, respectively). This can also explain the lower $\mathrm{CO}_{2} / \mathrm{CH}_{4}$ selectivity presented by the 


\section{ACCEPTED MANUSCRIPT}

MMMs; the higher the permeability of $\mathrm{CO}_{2}$, the greater the tendency of PIM-1 to be plasticized, swelling the polymer matrix and thus resulting in increased $\mathrm{CH}_{4}$ permeability [37].

(a)

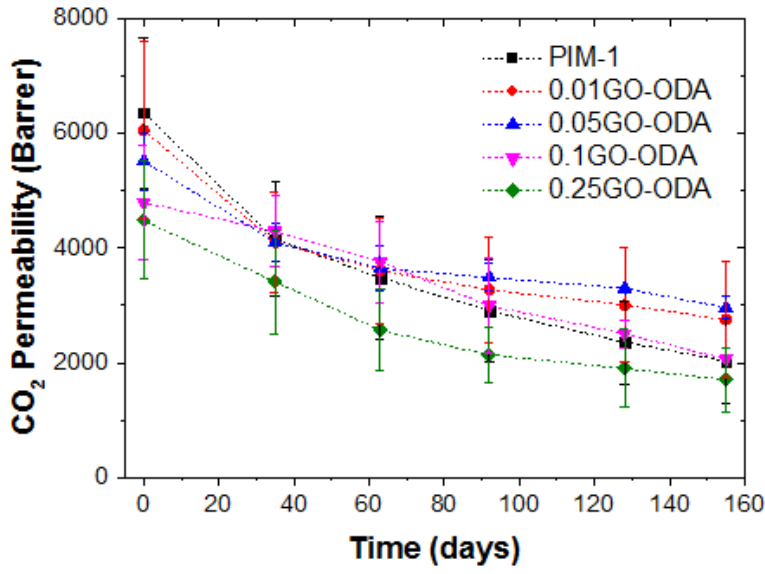

(c)

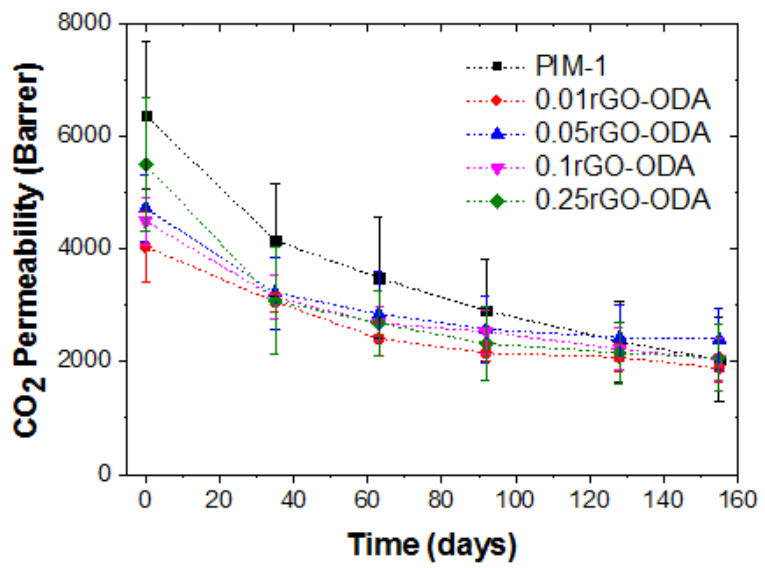

(e)

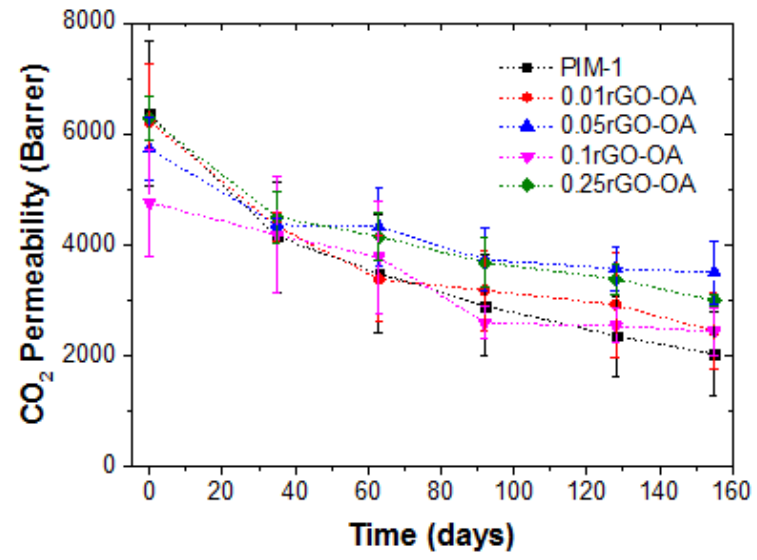

(b)

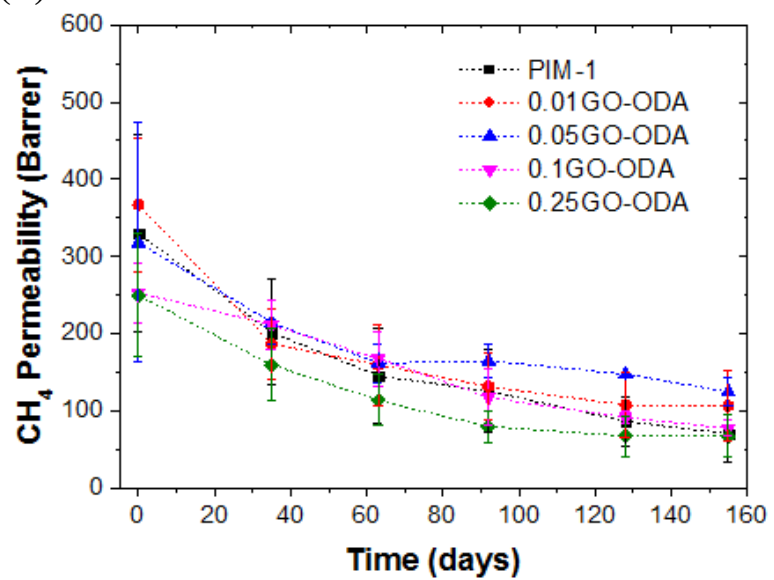

(d)

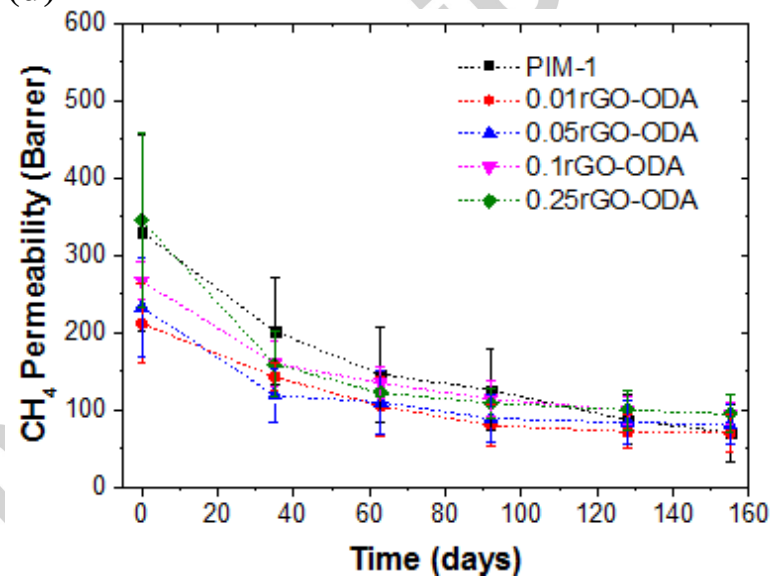

(f)

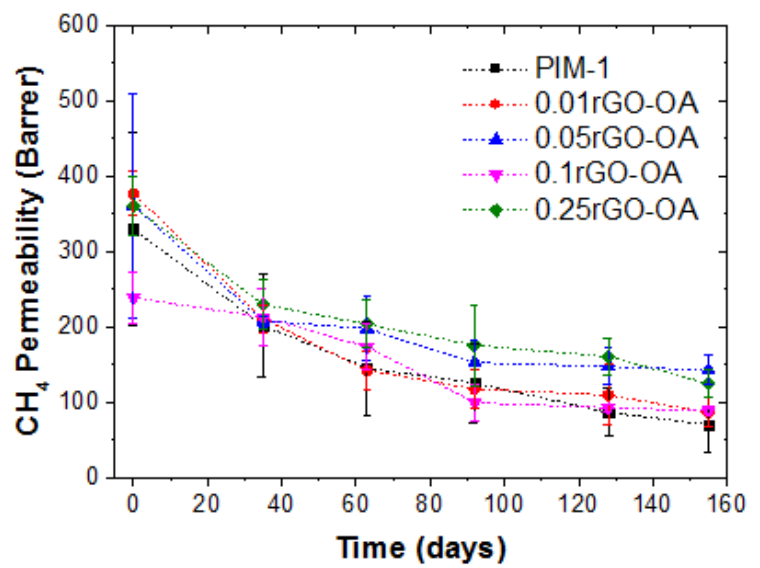

Fig. 3. $\mathrm{CO}_{2}$ and $\mathrm{CH}_{4}$ permeabilities of PIM-1 and MMMs with (a) (b) GO-ODA, (c) (d) rGO-ODA and (e) (f) rGO-OA incorporated into the polymer matrix. A 50:50 vol. $\% \mathrm{CO}_{2}$ and $\mathrm{CH}_{4}$ gas mixture was used as feed. Membranes were tested at $25{ }^{\circ} \mathrm{C}$, under a transmembrane pressure 2 bar. At least two membranes of each type were tested. The error bars correspond to the standard deviation. 
(a)

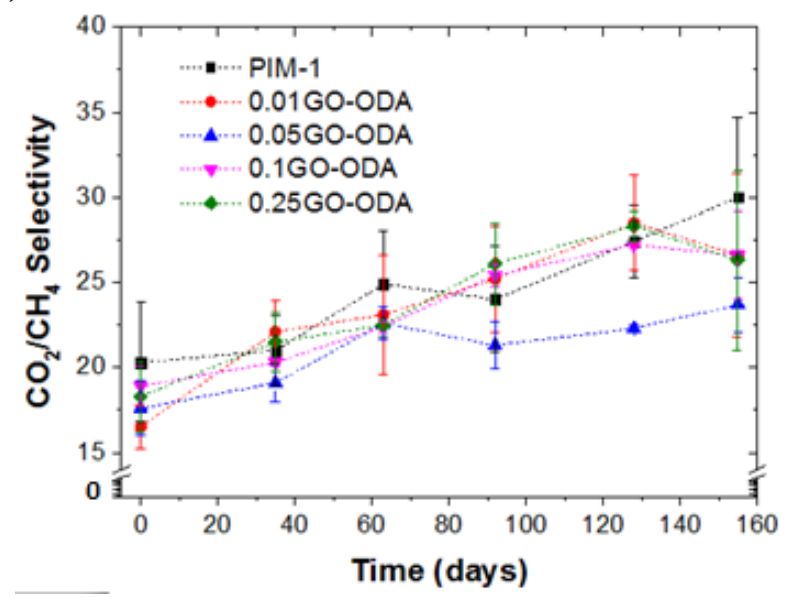

(b)

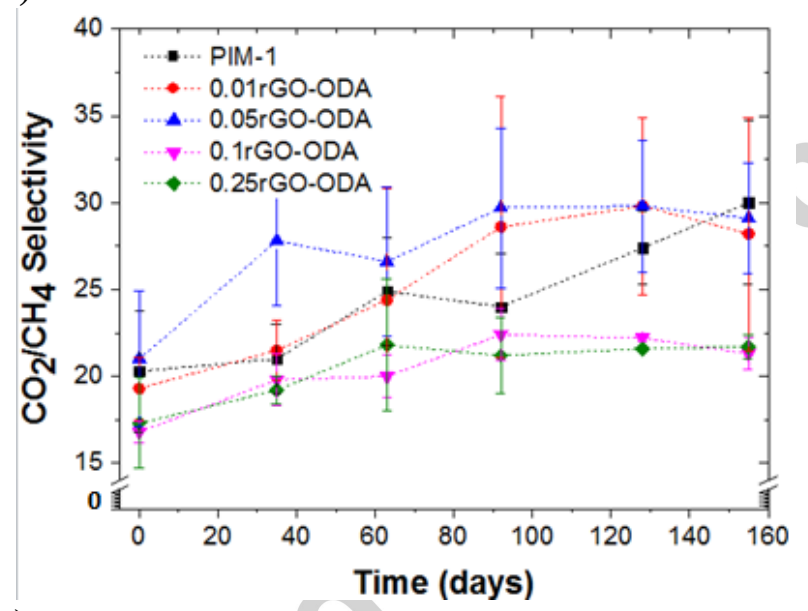

(c)

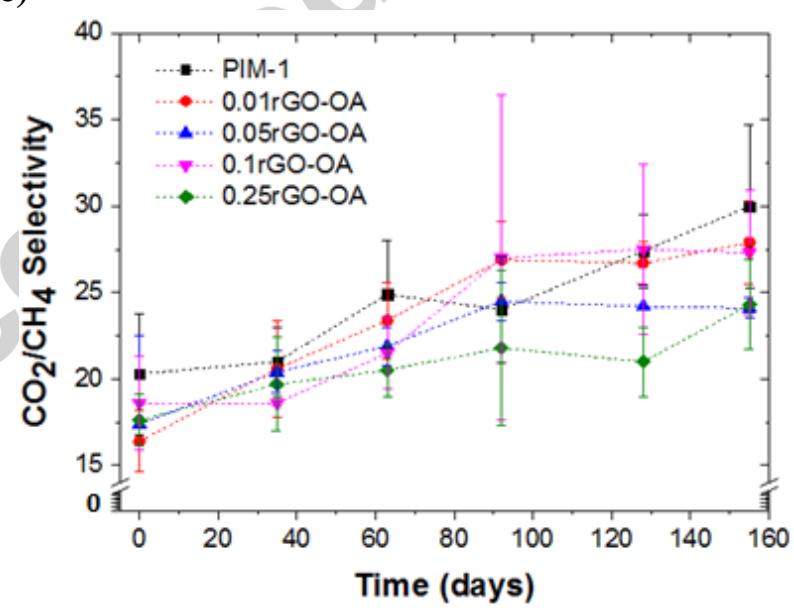

Fig. 4. $\mathrm{CO}_{2} / \mathrm{CH}_{4}$ selectivity of pristine PIM-1 membranes and MMMs filled with (a) GO-ODA, (b) rGO-Oda and (c) rGO-OA. At least two membranes of each type were tested and the error bars correspond to the standard deviation. 


\section{ACCEPTED MANUSCRIPT}

Robeson's diagrams, log-log plots of selectivity versus permeability of the more permeable gas for binary gas mixtures, are commonly used for evaluating the performance of membranes for gas separation processes. Robeson introduced in 1991 the concept of an "upper bound" relation [45] to represent the performance trade-off of polymeric membranes. The upper bound for different gas mixtures was revisited by Robeson in 2008, as new type of membrane materials including PIM-1 started to emerge, and the limits were pushed forward [46]. According to the results obtained in this work, all membranes' performance lay above the 2008 Robeson upper bound and move parallel to it over time in the direction of lower permeability and higher selectivity, as seen in Fig. 5. This behaviour is also reported by Williams et.al. [47], and suggests that the molecular transport is governed by the polymer matrix. Moreover, the performance of all aged MMMs lay on the right hand side of the aged PIM-1 membrane on the line parallel to the upper bound, despite having lower $\mathrm{CO}_{2}$ permeability than pristine PIM-1 when fresh (tested at day 0). Thus, suggesting that the incorporation of graphene-based fillers into PIM-1 lowers the rate of physical aging. It is worth mentioning that one possible explanation for having the pure PIM-1 membrane in this work above the 2008 upper bound might be the use of mixed gas feed; early PIM-1 data, which helped to define the 2008 upper bound, were based on single gas measurements (i.e. ideal gas selectivity values). In addition, the selectivity depends on the operating conditions such as temperature and pressure, and these are rarely the same between studies. 


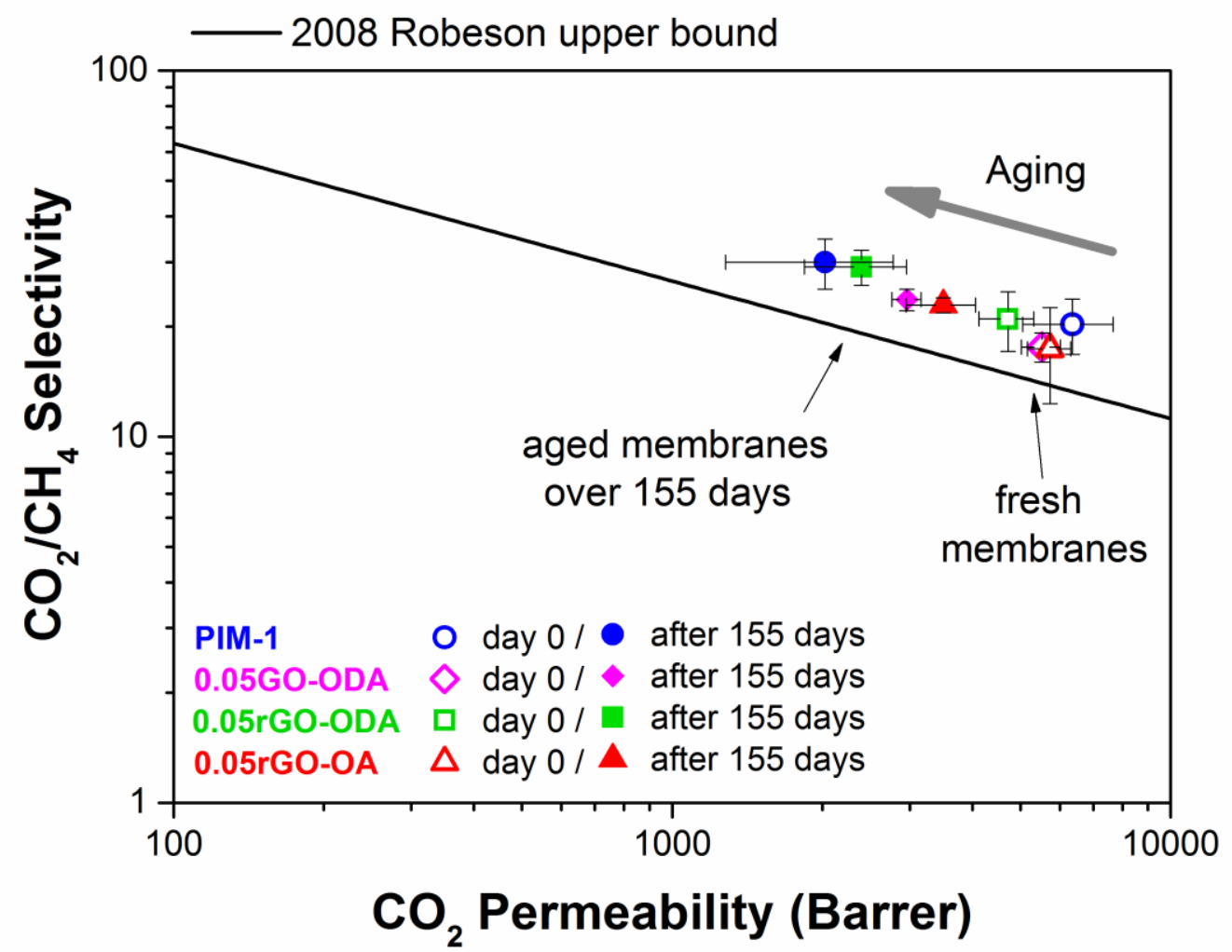

Fig. 5. $\mathrm{CO}_{2} / \mathrm{CH}_{4}$ selectivity vs $\mathrm{CO}_{2}$ permeability for pure PIM-1 and MMMs containing 0.05 wt.\% of graphene-based fillers. Values represent the average of at least two membranes and error bars correspond to the standard deviation obtained. Robeson's 2008 upper bound is also plotted. Open and solid symbols correspond to the performance of membranes on day 0 (fresh membranes) and after 155 days (aged membranes), respectively.

For comparison, representative data from the literature are presented in Table 3. The gas separation performance of aged pristine PIM-1 membranes developed in this study is comparable to values reported in the literature $[10,21,29]$. Small discrepancies might be found, possibly due to differences in operating temperature, feed composition and transmembrane pressures during testing, and variations in the PIM-1 itself. Moreover, the addition of fillers into polymer matrices can lead to the retardation of the physical aging. The incorporation of PAF-1- $\mathrm{Li}_{6} \mathrm{C}_{60}(10 \mathrm{wt} . \%)$ into PTMSP, a super glassy polymer, slowed physical aging as well as enhanced gas permeabilities, due to an increase in $\mathrm{CO}_{2}$ sorption [30]. Mitra et al. reported the use of crosslinked fillers (HCP) as a potential strategy to slow physical aging [21]. Therein, not only membranes aged at lower rate but also permeabilities were enhanced. More recently, Kinoshita et al. investigated the effect of physical aging on MMMs containing polyhedral oligomeric silsesquioxane (POSS) fillers 


\section{ACCEPTED MANUSCRIPT}

dispersed in PIM-1 [29]. Their results showed that the addition of 5 wt.\% of aminofunctionalized POSS particles could effectively retard physical aging, potentially caused by the rigidification of the polymer matrix.

It is worth mentioning that in the present study small loadings of graphene-like materials into PIM-1 membranes (as little as 0.05 wt.\%) are sufficient to see effective reductions in aging, as compared to typical values of filler concentrations found in the literature and shown in Table 3.

Table 3. Comparison of data obtained in this work with other data found in the literature.

\begin{tabular}{|c|c|c|c|c|c|}
\hline \multirow{2}{*}{ Membrane } & \multirow{2}{*}{ Day } & \multicolumn{2}{|c|}{ Permeability (Barrer) } & \multirow{2}{*}{$\begin{array}{c}\mathrm{CO}_{2} / \mathrm{CH}_{4} \\
\text { Selectivity }\end{array}$} & \multirow{2}{*}{ Ref. } \\
\hline & & $\mathrm{CO}_{2}$ & $\mathrm{CH}_{4}$ & & \\
\hline PIM-1 & 0 & $(6.4 \pm 1.3) \times 10^{3}$ & $(3.3 \pm 1.3) \times 10^{2}$ & $20.3 \pm 3.5$ & \multirow{8}{*}{$\begin{array}{l}\text { This } \\
\text { work }\end{array}$} \\
\hline PIM-1 & 155 & $(2.0 \pm 0.7) \times 10^{3}$ & $(0.7 \pm 0.4) \times 10^{2}$ & $30.0 \pm 4.7$ & \\
\hline $0.05 \mathrm{GO}-\mathrm{ODA}$ & 0 & $(5.5 \pm 0.5) \times 10^{3}$ & $(3.2 \pm 1.6) \times 10^{2}$ & $17.6 \pm 1.6$ & \\
\hline $0.05 \mathrm{GO}-\mathrm{ODA}$ & 155 & $(3.0 \pm 0.2) \times 10^{3}$ & $(1.3 \pm 0.2) \times 10^{2}$ & $23.7 \pm 1.6$ & \\
\hline $0.05 \mathrm{rGO}-\mathrm{ODA}$ & 0 & $(4.7 \pm 0.6) \times 10^{3}$ & $(2.3 \pm 0.7) \times 10^{2}$ & $21.0 \pm 3.9$ & \\
\hline $0.05 \mathrm{rGO}-\mathrm{ODA}$ & 155 & $(2.4 \pm 0.6) \times 10^{3}$ & $(0.8 \pm 0.3) \times 10^{2}$ & $29.1 \pm 3.2$ & \\
\hline $0.05 \mathrm{rGO}-\mathrm{OA}$ & 0 & $(5.7 \pm 0.6) \times 10^{3}$ & $(3.6 \pm 1.5) \times 10^{2}$ & $17.4 \pm 5.1$ & \\
\hline $0.05 \mathrm{rGO}-\mathrm{OA}$ & 155 & $(3.5 \pm 0.6) \times 10^{3}$ & $(1.4 \pm 0.2) \times 10^{2}$ & $24.1 \pm 0.6$ & \\
\hline PTMSP & 0 & 29000 & 13000 & 2.2 & \multirow{4}{*}[30]{} \\
\hline PTMSP & 365 & 7000 & 1200 & 5.8 & \\
\hline $\begin{array}{l}10 \text { wt. } \% \text { PAF-1- } \\
\mathrm{Li}_{6} \mathrm{C}_{60} / \mathrm{PTMSP}\end{array}$ & 0 & 53000 & 14000 & 3.6 & \\
\hline $\begin{array}{l}10 \text { wt. } \% \text { PAF-1- } \\
\mathrm{Li}_{6} \mathrm{C}_{60} / \mathrm{PTMSP}\end{array}$ & 365 & 50600 & 14000 & 3.6 & \\
\hline PIM-1 & 0 & 8221 & & & \multirow{4}{*}[21]{} \\
\hline PIM-1 & 150 & 2767 & & & \\
\hline 16.67 wt.\% HCP/PIM-1 & 0 & 19086 & & & \\
\hline 16.67 wt.\% HCP/PIM-1 & 150 & 9972 & & & \\
\hline PIM-1 & 0 & 13300 & 1150 & $11.6^{*}$ & \multirow{2}{*}{ [10] } \\
\hline PIM-1 & 1200 & 2840 & 159 & $17.8^{*}$ & \\
\hline PIM-1 & 0 & 4087 & 335 & $12.2 *$ & \multirow{4}{*}{ [29] } \\
\hline PIM-1 & 90 & 2000 & 118 & $16.9 *$ & \\
\hline 5 wt.\% OAPS/PIM-1 & 0 & 3266 & 157 & $16.2 *$ & \\
\hline 5 wt.\% OAPS/PIM-1 & 90 & 2400 & 130 & $18.5^{*}$ & \\
\hline $\mathrm{TR}$ & 0 & 105 & 4.4 & $23.8 *$ & \multirow{4}{*}[12]{} \\
\hline TR & 150 & 94 & & & \\
\hline $0.5 \mathrm{wt} . \% \mathrm{TR}+\mathrm{CNT}$ & 0 & 126 & 4.9 & $25.8 *$ & \\
\hline 0.5 wt. $\%$ TR+CNT & 145 & 110 & & & \\
\hline
\end{tabular}

1 Barrer $=3.34 \times 10^{-16} \mathrm{~mol} \mathrm{~m} \mathrm{~m}^{-2} \mathrm{~s}^{-1} \mathrm{~Pa}^{-1}$.

*Ideal selectivity. 


\section{ACCEPTED MANUSCRIPT}

\section{Conclusions}

In summary, the strategy of incorporating graphene-like materials into a PIM-1 polymer matrix is, indeed, an effective approach to retard the physical aging of PIM-1 membranes, and therefore, to develop high performance gas separation membranes. From our study on gas permeability, the best improvements regarding the impediment of physical aging were achieved by the MMMs with low loadings of graphene-like materials; 0.05GO-ODA, 0.05rGO-ODA and 0.05rGO-OA registered a decrease in $\mathrm{CO}_{2}$ permeability of $46 \%, 49 \%$ and $39 \%$, respectively, after 155 days. On the other hand, $\mathrm{CO}_{2}$ permeability of PIM-1 membranes decreased $68.1 \%$ after the same period of time. Moreover, 0.05 rGO-OA presented the highest $\mathrm{CO}_{2}$ permeability after 155 days of testing, $(3.5 \pm 0.6)$ x $10^{3}$ Barrer, which was $73 \%$ higher than pristine PIM-1 membranes.

While the results obtained in this study are promising, continuous testing should be carried out in order to evaluate the performance of membranes under similar conditions to those under industrial operations. Moreover, flux could be potentially increased if the hybrid PIM-1/graphene-like materials were presented as thin film composite membranes, making them more competitive for industrial applications. However, aging should be evaluated as it is highly dependent on the film thickness.

\section{Acknowledgments}

The authors thank the EPSRC for funding (EP/K016946/1 and EP/M001342/1). M. Alberto and J. M. Luque-Alled thank to the School of Chemical Engineering and Analytical Science - The University of Manchester for funding their PhD studies.

All research data supporting this publication are directly available within this publication and the corresponding Supplementary Material, as well as available from the corresponding author upon reasonable request. 


\section{ACCEPTED MANUSCRIPT}

\section{References}

[1] W.M. Organization, World Meteorological Organization's Greenhouse Gas Bulletin., (2017).

[2] Y. Zhang, J. Sunarso, S. Liu, R. Wang, Current status and development of membranes for CO2/CH4 separation: A review, Int. J Greenh. Gas. Con., 12 (2013) 84-107.

[3] Y. Alcheikhhamdon, M. Hoorfar, Natural gas purification from acid gases using membranes: A review of the history, features, techno-commercial challenges, and process intensification of commercial membranes, Chem. Eng. Process., 120 (2017) 105-113.

[4] Y. Cheng, X. Wang, C. Jia, Y. Wang, L. Zhai, Q. Wang, D. Zhao, Ultrathin mixed matrix membranes containing two-dimensional metal-organic framework nanosheets for efficient $\mathrm{CO} 2 / \mathrm{CH} 4$ separation, J. Membr. Sci., 539 (2017) 213-223.

[5] P.M. Budd, E.S. Elabas, B.S. Ghanem, S. Makhseed, N.B. McKeown, K.J. Msayib, C.E. Tattershall, D. Wang, Solution-Processed, Organophilic Membrane Derived from a Polymer of Intrinsic Microporosity, Adv. Mater., 16 (2004) 456-459.

[6] P. Gorgojo, S. Karan, H.C. Wong, M.F. Jimenez-Solomon, J.T. Cabral, A.G. Livingston, Ultrathin Polymer Films with Intrinsic Microporosity: Anomalous Solvent Permeation and High Flux Membranes, Adv. Funct. Mater., 24 (2014) 4729-4737.

[7] L. Gao, M. Alberto, P. Gorgojo, G. Szekely, P.M. Budd, High-flux PIM-1/PVDF thin film composite membranes for 1-butanol/water pervaporation, J. Membr. Sci., 529 (2017) 207-214.

[8] M.L. Jue, V. Breedveld, R.P. Lively, Defect-free PIM-1 hollow fiber membranes, J. Membr. Sci., 530 (2017) 33-41.

[9] P.M. Budd, K.J. Msayib, C.E. Tattershall, B.S. Ghanem, K.J. Reynolds, N.B. McKeown, D. Fritsch, Gas separation membranes from polymers of intrinsic microporosity, J. Membr. Sci., 251 (2005) 263-269.

[10] P. Bernardo, F. Bazzarelli, F. Tasselli, G. Clarizia, C.R. Mason, L. Maynard-Atem, P.M. Budd, M. Lanč, K. Pilnáček, O. Vopička, K. Friess, D. Fritsch, Y.P. Yampolskii, V. Shantarovich, J.C. Jansen, Effect of physical aging on the gas transport and sorption in PIM-1 membranes, Polymer, 113 (2017) 283-294. 


\section{ACCEPTED MANUSCRIPT}

[11] P.M. Budd, Polymer with Intrinsic Microporosity (PIM), in: E. Drioli, L. Giorno (Eds.) Encyclopedia of Membranes, Springer Berlin Heidelberg, Berlin, Heidelberg, 2016, pp. 1606-1607.

[12] A. Brunetti, M. Cersosimo, J.S. Kim, G. Dong, E. Fontananova, Y.M. Lee, E. Drioli, G. Barbieri, Thermally rearranged mixed matrix membranes for $\mathrm{CO} 2$ separation: An aging study, Int. J Greenh. Gas. Con., 61 (2017) 16-26.

[13] A.A. Shamsabadi, R.M. Behbahani, F. Seidi, M. Soroush, Physical aging of polyetherimide membranes, J. Nat. Gas Sci. Eng., 27 (2015) 651-660.

[14] L. Xu, M. Rungta, J. Hessler, W. Qiu, M. Brayden, M. Martinez, G. Barbay, W.J. Koros, Physical aging in carbon molecular sieve membranes, Carbon, 80 (2014) 155-166.

[15] Y. Huang, D.R. Paul, Effect of Film Thickness on the Gas-Permeation Characteristics of Glassy Polymer Membranes, Ind. Eng. Chem. Res., 46 (2007) 2342-2347.

[16] K. Nagai, T. Nakagawa, Effects of aging on the gas permeability and solubility in poly(1trimethylsilyl-1-propyne) membranes synthesized with various catalysts, J. Membr. Sci., 105 (1995) 261-272.

[17] R.R. Tiwari, J. Jin, B.D. Freeman, D.R. Paul, Physical aging, CO2 sorption and plasticization in thin films of polymer with intrinsic microporosity (PIM-1), J. Membr. Sci., 537 (2017) 362-371.

[18] S. Harms, K. Rätzke, F. Faupel, N. Chaukura, P.M. Budd, W. Egger, L. Ravelli, Aging and Free Volume in a Polymer of Intrinsic Microporosity (PIM-1), J. Adhes., 88 (2012) 608-619.

[19] Y. Huang, D.R. Paul, Effect of Temperature on Physical Aging of Thin Glassy Polymer Films, Macromolecules, 38 (2005) 10148-10154.

[20] K. Nagai, A. Higuchi, T. Nakagawa, Gas permeability and stability of poly(1-trimethylsilyl-1propyne-co-1-phenyl-1-propyne) membranes, Journal of Polymer Science Part B: Polymer Physics, 33 (1995) 289-298.

[21] T. Mitra, R.S. Bhavsar, D.J. Adams, P.M. Budd, A.I. Cooper, PIM-1 mixed matrix membranes for gas separations using cost-effective hypercrosslinked nanoparticle fillers, Chem. Commun., 52 (2016) 5581-5584.

[22] P.M. Budd, N.B. McKeown, B.S. Ghanem, K.J. Msayib, D. Fritsch, L. Starannikova, N. Belov, O. Sanfirova, Y. Yampolskii, V. Shantarovich, Gas permeation parameters and other physicochemical 


\section{ACCEPTED MANUSCRIPT}

properties of a polymer of intrinsic microporosity: Polybenzodioxane PIM-1, J. Membr. Sci., 325 (2008) 851-860.

[23] H. Shamsipur, B.A. Dawood, P.M. Budd, P. Bernardo, G. Clarizia, J.C. Jansen, Thermally Rearrangeable PIM-Polyimides for Gas Separation Membranes, Macromolecules, 47 (2014) 55955606.

[24] K. Pilnáček, O. Vopička, M. Lanč, M. Dendisová, M. Zgažar, P.M. Budd, M. Carta, R. MalpassEvans, N.B. McKeown, K. Friess, Aging of polymers of intrinsic microporosity tracked by methanol vapour permeation, J. Membr. Sci., 520 (2016) 895-906.

[25] F.Y. Li, Y. Xiao, T.-S. Chung, S. Kawi, High-Performance Thermally Self-Cross-Linked Polymer of Intrinsic Microporosity (PIM-1) Membranes for Energy Development, Macromolecules, 45 (2012) 1427-1437.

[26] Q. Song, S. Cao, R.H. Pritchard, B. Ghalei, S.A. Al-Muhtaseb, E.M. Terentjev, A.K. Cheetham, E. Sivaniah, Controlled thermal oxidative crosslinking of polymers of intrinsic microporosity towards tunable molecular sieve membranes, Nat. Commun., 5 (2014).

[27] B. Ghalei, Y. Kinoshita, K. Wakimoto, K. Sakurai, S. Mathew, Y. Yue, H. Kusuda, H. Imahori, E. Sivaniah, Surface functionalization of high free-volume polymers as a route to efficient hydrogen separation membranes, J. Mater. Chem. A, 5 (2017) 4686-4694.

[28] S.D. Kelman, B.W. Rowe, C.W. Bielawski, S.J. Pas, A.J. Hill, D.R. Paul, B.D. Freeman, Crosslinking poly[1-(trimethylsilyl)-1-propyne] and its effect on physical stability, J. Membr. Sci., 320 (2008) 123-134.

[29] Y. Kinoshita, K. Wakimoto, A.H. Gibbons, A.P. Isfahani, H. Kusuda, E. Sivaniah, B. Ghalei, Enhanced PIM-1 membrane gas separation selectivity through efficient dispersion of functionalized POSS fillers, J. Membr. Sci., 539 (2017) 178-186.

[30] C.H. Lau, K. Konstas, C.M. Doherty, S. Kanehashi, B. Ozcelik, S.E. Kentish, A.J. Hill, M.R. Hill, Tailoring Physical Aging in Super Glassy Polymers with Functionalized Porous Aromatic Frameworks for CO2 Capture, Chem. Mater., 27 (2015) 4756-4762.

[31] M. Alberto, J.M. Luque-Alled, L. Gao, M. Iliut, E. Prestat, L. Newman, S.J. Haigh, A. Vijayaraghavan, P.M. Budd, P. Gorgojo, Enhanced organophilic separations with mixed matrix 


\section{ACCEPTED MANUSCRIPT}

membranes of polymers of intrinsic microporosity and graphene-like fillers, J. Membr. Sci., 526 (2017) 437-449.

[32] A. Gonciaruk, K. Althumayri, W.J. Harrison, P.M. Budd, F.R. Siperstein, PIM-1/graphene composite: A combined experimental and molecular simulation study, Micropor. Mesopor. Mater., 209 (2015) 126-134.

[33] K. Althumayri, W.J. Harrison, Y.Y. Shin, J.M. Gardiner, C. Casiraghi, P.M. Budd, P. Bernardo, G. Clarizia, J.C. Jansen, The influence of few-layer graphene on the gas permeability of the high-freevolume polymer PIM-1, Philos. Trans. A. Math. Phys. Eng. Sci., 374 (2016).

[34] N.Y. Du, J.S. Song, G.P. Robertson, I. Pinnau, M.D. Guiver, Linear high molecular weight ladder polymer via fast polycondensation of 5,5',6,6'-tetrahydroxy-3,3,3',3'-tetramethylspirobisindane with 1,4-dicyanotetrafluorobenzene, Macromol. Rap. Commun., 29 (2008) 783-788.

[35] J.P. Rourke, P.A. Pandey, J.J. Moore, M. Bates, I.A. Kinloch, R.J. Young, N.R. Wilson, The Real Graphene Oxide Revealed: Stripping the Oxidative Debris from the Graphene-like Sheets, Angew. Chem. Int. Ed., 50 (2011) 3173-3177.

[36] N. Tien-Binh, H. Vinh-Thang, X.Y. Chen, D. Rodrigue, S. Kaliaguine, Crosslinked MOFpolymer to enhance gas separation of mixed matrix membranes, J. Membr. Sci., 520 (2016) 941-950.

[37] X. Wu, W. Liu, H. Wu, X. Zong, L. Yang, Y. Wu, Y. Ren, C. Shi, S. Wang, Z. Jiang, Nanoporous ZIF-67 embedded polymers of intrinsic microporosity membranes with enhanced gas separation performance, J. Membr. Sci., 548 (2018) 309-318.

[38] X.Y. Wu, Z.Z. Tian, S.F. Wang, D.D. Peng, L.X. Yang, Y.Z. Wu, Q.P. Xin, H. Wu, Z.Y. Jiang, Mixed matrix membranes comprising polymers of intrinsic microporosity and covalent organic framework for gas separation, J. Membr. Sci., 528 (2017) 273-283.

[39] B. Shen, W. Zhai, M. Tao, D. Lu, W. Zheng, Chemical functionalization of graphene oxide toward the tailoring of the interface in polymer composites, Compos. Sci. Technol., 77 (2013) 87-94. [40] Z. Tian, S. Wang, Y. Wang, X. Ma, K. Cao, D. Peng, X. Wu, H. Wu, Z. Jiang, Enhanced gas separation performance of mixed matrix membranes from graphitic carbon nitride nanosheets and polymers of intrinsic microporosity, J. Membr. Sci., 514 (2016) 15-24. 


\section{ACCEPTED MANUSCRIPT}

[41] X. Wang, D. Tan, Z. Chu, L. Chen, X. Chen, J. Zhao, G. Chen, Mechanical properties of polymer composites reinforced by functionalized graphene prepared via direct exfoliation of graphite flakes in styrene, RSC Adv., 6 (2016) 112486-112492.

[42] C. Lee, X. Wei, J.W. Kysar, J. Hone, Measurement of the Elastic Properties and Intrinsic Strength of Monolayer Graphene, Science, 321 (2008) 385-388.

[43] S. Ebrahimzadeh, B. Ghanbarzadeh, H. Hamishehkar, Physical properties of carboxymethyl cellulose based nano-biocomposites with Graphene nano-platelets, Int. J, Biol. Macromol., 84 (2016) $16-23$.

[44] A. Kumar, D.K. Chouhan, P.S. Alegaonkar, T.U. Patro, Graphene-like nanocarbon: An effective nanofiller for improving the mechanical and thermal properties of polymer at low weight fractions, Compos. Sci. Technol., 127 (2016) 79-87.

[45] L.M. Robeson, Correlation of separation factor versus permeability for polymeric membranes, J. Membr. Sci., 62 (1991) 165-185.

[46] L.M. Robeson, The upper bound revisited, J. Membr. Sci., 320 (2008) 390-400.

[47] R. Williams, L.A. Burt, E. Esposito, J.C. Jansen, E. Tocci, C. Rizzuto, M. Lanc, M. Carta, N.B. McKeown, A highly rigid and gas selective methanopentacene-based polymer of intrinsic microporosity derived from Troger's base polymerization, J. Mater. Chem. A, 6 (2018) 5661-5667. 